\title{
Historical development of health professions' education in the Arab world
}

\author{
N.M. Kronfol ${ }^{l}$
}

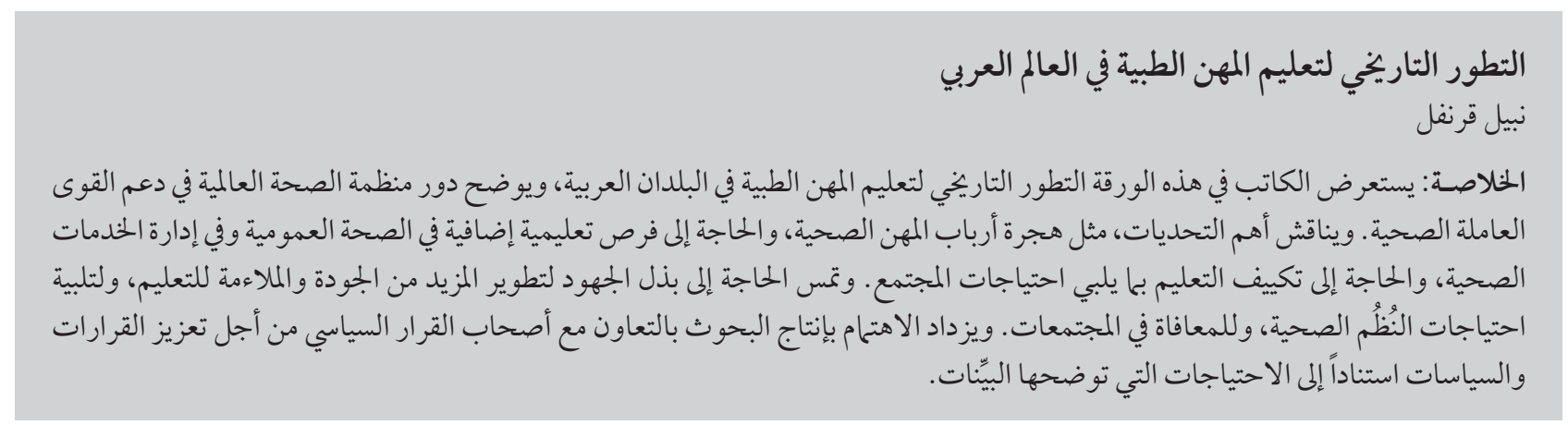

ABSTRACT This paper reviews the historical development of health professions' education in the Arab countries and highlights the role that the World Health Organization has played in the support of the health workforce. Challenges such as the migration of health professionals, the need for additional educational opportunities in public health and in the management of health services and the need to adapt education to address the needs of society are discussed. Efforts are needed to develop further the quality and relevance of education and to address the needs of the health systems and the welfare of communities. The production of research in cooperation with policy-makers to enhance decisions and policies based on evidence needs increased attention.

\section{Développement historique de la formation aux professions de la santé dans le monde arabe}

RÉSUMÉ Le présent article examine le développement historique de la formation aux professions de la santé dans les pays arabes et souligne le rôle que l'Organisation mondiale de la santé a joué dans l'appui aux personnels de santé. Les difficultés telles que la migration des professionnels de santé, la nécessité d'opportunités de formation supplémentaires en santé publique et en gestion des services de santé ainsi que l'adaptation nécessaire de la formation en réponse aux besoins de la société sont abordées. Des efforts sont nécessaires pour obtenir une formation de meilleure qualité et d'une pertinence accrue et pour répondre aux besoins des systèmes de santé et améliorer le bien-être des communautés. La production de recherches en coopération avec les décideurs politiques pour renforcer les décisions et les politiques fondées sur des bases factuelles requiert une attention accrue. 


\section{Introduction}

The evolution of the health workforce has been one of the most impressive achievements that have occurred in the health systems of the Arab countries in the past 3 decades. In parallel with the rapid developments in the health services in the Arab region [1], there has also been great progress in training the health workforce in the region. This paper is the second in a series of five reviews about health services in the Arab region [1-4]. It reviews the historical development of health professions' education in the Arab countries, highlighting the role that the World Health Organization (WHO) has played over past decades in the support of human resources in health and the changing needs in the various member states. The migration of health professionals is also highlighted with a particular focus on the nursing profession. Training in public health and the management of health services is singled out as a pressing need for the future development of health services.

\section{Early years}

Established by the French after Napoleon's invasion of Egypt, Qasr Al Aini is the oldest hospital and medical college in the region. Later developments included the arrival of religious missions in the Levant after the events of 1860 in Mount Lebanon: In 1866, the Syrian Protestant College was established, to be followed 1 year later with the intake of the first medical students at this College. The first cohort to medical graduates from this College was in 1871 in Beirut. In 1887, Jesuit missionaries in Beirut established the Université SaintJoseph which included a medical college. These 2 medical colleges were to play an important role in the provision of medical services in the Region as well as medical and nursing education. At the turn of the 20th century, American missionaries established hospitals in Bahrain in 1900 and in Muscat, Oman. Government-funded medical colleges started to be established soon after the end of the First World War in Egypt, Syrian Arab Republic, Iraq and Sudan. In the mid-1960s and early 1970s, medical schools were established by the governments of Jordan, Kuwait, Saudi Arabia and Iraq. In the mid 1980s, the University of Al Ain Faculty of Health Sciences was established in the United Arab Emirates (UAE), to be followed by medical schools in Oman, Dubai and Ajman (UAE) and Yemen.

Most of the medical schools in the region were established and funded by governments. However, in the past few years, privately funded medical colleges, mostly for-profit institutions, have been established, for example in Bahrain, UAE and Sudan. Other private medical colleges are being considered in the region. Another trend over the past few years has been the affiliation of medical colleges with prestigious institutions in the developed world. The Bahrain Medical College is managed by the College of Physicians and Surgeons of Ireland. Weil Cornell University has established a branch in Qatar, funded by the Qatar Foundation for Science and Education. The Gulf Medical College in Ajman has a collaborative arrangement with the University of West Virginia in the United States. The newly established faculty of medicine in the University of Sharjah entered into a contractual agreement with University of Monash in Australia.

\section{Current situation}

A closer examination of the data on Arab countries shows wide disparities in the ratios of the health workforce per 10000 population across the countries in all categories. To illustrate, whereas the proportion of physicians per 10000 was 1.8 in Djibouti in 2005, that ratio was greater than 20 in Egypt, Jordan,
Bahrain and reached 29 in Lebanon. The proportion of nurses showed even greater disparity, ranging from 5.7 per 10000 population in Yemen to more than 30 in Tunisia, Jordan, Egypt, Kuwait and Oman, even reaching 55 in Bahrain and 74 in Qatar(Table 1). It should be noted in this respect that the Arab countries have succeeded in developing their human resources within one generation, moving from a shortage of physicians in the early 1970s to an overabundance in some countries by the turn of the century. To illustrate, the ratio of physicians per 10000 population increased by only $40 \%$ between 1970 and 2005 in Djibouti but rose 22.5-fold in Yemen and 44.8-fold in Oman. Most countries had 4-8 times the numbers of physicians per 10000 population in 2005 versus 1970 (Table 2)

The development of human resources in the Arab countries has resulted from major efforts expended by governments to establish educational institutions for all categories of human resources. For example the number of medical colleges in the Arab region rose from only 8 in 1950 to 161 in 2005, due to the growth in the number of private medical colleges since the 1990s (Table 3).

\section{Development of the nursing profession}

The changes in the density of nurses from 1970 to 2000 are shown in Table 4. In some countries the density has increased dramatically and in others the figure is very low and has fallen. The poor social status of the nursing profession makes nursing an unattractive career choice for the nationals of some countries in the Arab region. The exception is Oman, which has successfully encouraged nationals to enter the profession through the establishment of district schools of nursing across the country, thus educating nurses to serve within their own communities. A study 


\begin{tabular}{|c|c|c|c|c|}
\hline \multicolumn{5}{|c|}{$\begin{array}{l}\text { Table } 1 \text { Density of medical staff in the Arab countries of the } \\
\text { Organization (WHO) Eastern Mediterranean Region, } 2005\end{array}$} \\
\hline \multirow[t]{2}{*}{ Country } & \multicolumn{4}{|c|}{ No. of staff per 10000 population } \\
\hline & Physicians & Dentists & Pharmacists & Nurses \\
\hline Bahrain & 27.6 & 4.1 & 8.3 & 55.0 \\
\hline Djibouti & 1.8 & 0.7 & 3.4 & 8.0 \\
\hline Egypt & 24.3 & 3.4 & 12.5 & 33.5 \\
\hline Iraq & 6.6 & 1.2 & 1.1 & 12.6 \\
\hline Jordan & 24.5 & 8.2 & 12.0 & 33.0 \\
\hline Kuwait & 18.0 & 3.0 & 2.0 & 37.0 \\
\hline Lebanon & 28.4 & 9.8 & 13.8 & 13.2 \\
\hline Libya & 12.5 & 2.5 & 2.0 & 48.0 \\
\hline Morocco & 5.6 & 1.1 & 2.3 & 9.0 \\
\hline Oman & 17.9 & 1.9 & 3.1 & 37.7 \\
\hline Palestine & 10.7 & 0.9 & 1.4 & 14.7 \\
\hline Qatar & 27.6 & 5.8 & 12.6 & 73.8 \\
\hline Saudi Arabia & 20.0 & 2.1 & 3.5 & 34.6 \\
\hline Sudan & 2.9 & 0.1 & 0.07 & 9.1 \\
\hline Syrian Arab Republic & 14.8 & 7.4 & 6.5 & 18.8 \\
\hline Tunisia & 9.5 & 1.8 & 2.0 & 31.4 \\
\hline UAE & 16.1 & 4.0 & 5.8 & 29.1 \\
\hline Yemen & 3.6 & 1.0 & 1.0 & 5.7 \\
\hline
\end{tabular}

Source: Annual reports of the Regional Director, WHO Regional Office for the Eastern Mediterranean. $U A E=$ United Arab Emirates; $P H C=$ primary health care. in Qatar was undertaken to identify female students' reasons for choosing nursing and how the students perceived the community's attitudes towards nursing as a career [5]. Students stated that their reasons for joining the nursing profession were their interest in medical work and the humanitarian nature of the nursing profession. These results are similar to those of Munro who investigated the motives and attitudes of young graduate nurses in the USA [6]. Most of the students in the Qatar study acknowledged, however, that there were negative attitude towards nursing. The main reasons given were that nursing involved contact with the opposite sex, whether patients or colleagues, and the pattern of working hours. These same reasons and the poor social image were also given for the refusal of Saudi parents to approve their sons or daughters joining the nursing profession [7]. This negative

\begin{tabular}{|c|c|c|c|c|c|c|}
\hline \multirow[t]{2}{*}{ Country } & \multicolumn{5}{|c|}{ No. of physicians per 10000 population } & \multirow{2}{*}{$\begin{array}{l}\text { Ratio of no. of physicians year } \\
2005 \text { to } 1970\end{array}$} \\
\hline & 1970 & 1990 & 1995 & 2000 & 2005 & \\
\hline Bahrain & 5.6 & 13.0 & 11.1 & 13.2 & 27.6 & 5.0 \\
\hline Djibouti & 4.6 & 2.1 & 2.0 & 1.3 & 1.8 & 0.4 \\
\hline Egypt & 5.0 & 17.3 & 20.2 & 21.8 & 24.3 & 4.9 \\
\hline Iraq & 1.7 & 5.8 & 5.1 & 5.5 & 6.6 & 4.0 \\
\hline Jordan & 2.9 & 18.3 & 15.8 & 19.8 & 24.5 & 8.6 \\
\hline Kuwait & 10.0 & 14.8 & 17.8 & 16.0 & 18.0 & 1.8 \\
\hline Lebanon & 6.7 & 8.9 & 19.1 & 29.2 & 28.4 & 4.3 \\
\hline Libya & 4.6 & 13.7 & 13.7 & 14.0 & 12.5 & 2.8 \\
\hline Morocco & - & 1.6 & 3.4 & 4.6 & 5.6 & - \\
\hline Oman & 0.4 & 8.6 & 12.0 & 13.5 & 17.9 & 44.8 \\
\hline Palestine & - & - & 0.9 & 9.4 & 10.7 & - \\
\hline Qatar & 8.3 & 18.2 & 14.3 & 20.1 & 27.6 & 3.3 \\
\hline Saudi Arabia & 1.0 & 18.8 & 16.6 & 17.1 & 20.0 & 20.0 \\
\hline Somalia & 0.6 & 0.6 & 0.4 & 0.4 & - & - \\
\hline Sudan & 0.5 & 1.0 & 1.0 & 1.5 & 2.9 & 5.5 \\
\hline Syrian Arab Republic & 2.9 & 8.6 & 10.9 & 13.1 & 14.8 & 5.2 \\
\hline Tunisia & 1.3 & 5.7 & 6.7 & 7.0 & 9.5 & 7.6 \\
\hline UAE & - & 17.5 & 16.8 & 17.8 & 16.1 & - \\
\hline Yemen & 0.2 & 1.4 & 2.6 & 3.5 & 3.6 & 22.5 \\
\hline
\end{tabular}

Source: Annual reports of the Regional Director, WHO Regional Office for the Eastern Mediterranean.

$U A E=$ United Arab Emirates. 


\begin{tabular}{|c|c|c|}
\hline \multirow[t]{2}{*}{ Country } & \multicolumn{2}{|c|}{ No. of colleges } \\
\hline & 1950 & 2006 \\
\hline Bahrain & 0 & 2 \\
\hline Djibouti & 0 & 1 \\
\hline Egypt & 3 & 26 \\
\hline Iraq & 1 & 20 \\
\hline Jordan & 0 & 4 \\
\hline Kuwait & 0 & 1 \\
\hline Lebanon & 2 & 4 \\
\hline Libya & 0 & 24 \\
\hline Morocco & 0 & 5 \\
\hline Oman & 0 & 2 \\
\hline Palestine & 0 & 2 \\
\hline Qatar & 0 & 1 \\
\hline Saudi Arabia & 0 & 12 \\
\hline Somalia & 0 & 3 \\
\hline Sudan & 1 & 30 \\
\hline Syrian Arab Republic & 1 & 6 \\
\hline Tunisia & 0 & 4 \\
\hline UAE & 0 & 6 \\
\hline Yemen & 0 & 8 \\
\hline Total & 8 & 161 \\
\hline
\end{tabular}

Source: Al Sheikh G, unpublished presentation at WHO meeting on human resources in Muscat, Oman, December 2006.

attitude existed even though both Saudi parents and university students recognized the humanitarian nature of nursing, and the religious, social and psychological reasons behind the need for Saudi national nurses. Similar findings have been reported from Jordan, Egypt and Kuwait [8-10]. The publication of Nursing education in the Eastern Mediterranean Region in 1998 by the World Health Organization Regional Office for the Eastern Mediterranean (WHO EMRO) facilitated the process of nursing education reform at the basic and post-basic specialist level [11]. This document was very well received and was regarded as an important tool for initiating change in nursing education.

To enhance the process of educational reform in the region, support by WHO EMRO has been provided to countries to strengthen the human and material resources of their educational institutions. This has included national training activities to promote capacity-building of teachers and the provision of nursing and midwifery literature, and audiovisual aids. In addition, fellowships have been awarded to teaching staff to increase their capabilities in educational methodology, community-oriented nursing curricula and clinical nursing subjects. All countries, without exception, have taken initiatives to improve basic nursing education through increasing the number of programmes, reorienting the curriculum towards the primary health care approach, training teachers and improving library and clinical skills laboratory resources. Most countries are now better able to attract students to nursing and midwifery programmes and the demand on nursing schools is increasing [11-16].
Migration of physicians, nurses $\&$ other health professionals

The migration of health personnel is a phenomenon that affects the health system of several Arab countries. While all GCC countries are net importers of health care staff, many middle and low-income countries are next exporters of health personnel both within and outside the region. The main exporting countries include Egypt, Sudan, Jordan, Syrian Arab Republic, Lebanon, Iraq, Morocco and Tunisia [17]. An important consideration, however, is whether the migration of personnel is temporary or permanent.

Since the early 1960s, migration from the Arab Maghreb countries to Europe has become a prominent social phenomenon that has raised considerable controversy in the European countries [18]. According to the United Nations Development Programme, Lebanon has lost more than 895000 people to permanent emigration since 1975, including 320000 skilled, educated individuals [19]. Of all medical graduates from the American University of Beirut over the period 1935-74, only $33.2 \%$ were practising in Lebanon in 1977 [20]. Yet this 40-year period was a period of prosperity in the country. A follow up of these graduates in 1984, 9 years after the beginning of the civil disturbances, revealed that only $16.5 \%$ had remained in the country [21]. Most of these remaining graduates were associated with academic medical centres [22].

Several medical colleges in the Arab region have designed and/or revised the medical curriculum based on the standards adopted in the industrialized countries, principally the United States. Their graduates have excelled in scoring on international examinations, as well as in postgraduate training in some of the best academic 


\begin{tabular}{lccc}
\hline Table 4 Changes in the density of nurses in Arab countries of the World Health \\
Organization (WHO) Eastern Mediterranean Region, 1970-2000 \\
\hline Country & \multicolumn{4}{c}{ No. of nurses } & (1000 population \\
& $\mathbf{1 9 7 0}$ & $\mathbf{1 9 8 0}$ & $\mathbf{2 0 0 0}$ \\
Bahrain & 26.4 & 30.2 & 45.7 \\
Djibouti & 27.9 & 8.8 & 8.0 \\
Egypt & 10.8 & 16.5 & 26.5 \\
Iraq & 3.5 & 6.1 & 12.1 \\
Jordan & 13.2 & 8.3 & 32.5 \\
Kuwait & 45.9 & 54.6 & 40.0 \\
Lebanon & 9.5 & 13.9 & 30.0 \\
Libya & 15.3 & 31.3 & 50.0 \\
Oman & 2.9 & 8.5 & 37.0 \\
Qatar & 25.8 & 35.4 & 54.8 \\
Saudi Arabia & 2.7 & 7.2 & 32.3 \\
Somalia & 3.4 & 5.2 & 2.0 \\
Sudan & 6.5 & 7.3 & 5.1 \\
Syrian Arab Republic & 3.7 & 8.9 & 18.8 \\
Tunisia & 14.1 & 11.7 & 36.4 \\
UAE & 10.5 & 40.0 & 35.2 \\
Yemen & - & 2.6 & 5.2 \\
\hline
\end{tabular}

Sources: [50,57].

medical centres in North America and Europe. However several studies have documented that this excellence in teaching resulted in a massive exodus of their medical graduates to occupy permanent positions in the country of postgraduate education, thus contributing to migration and the loss of excellent human resources from the region [20-24]. This has been the experience at Pahlevi University in Shiraz in the Islamic Republic of Iran (prior to 1979) [23], the American University of Beirut in Lebanon [2022] and more recently the Aga Khan University in Karachi, Pakistan [N. Kronfol, unpublished observations].

\section{Migration of nursing professionals}

The international migration of nurses from the region first emerged as a major public health issue in the 1940s, when many nurses emigrated to the United Kingdom and the United States. By the mid-1960s, the losses were causing concern. Migration has continued and the international recruitment of nurses from the region has become prominent features in the last few years. While there is nothing new in nurses moving across borders, what has changed in recent years is the increase in active recruitment by employers from developed countries that are facing nursing shortages.

The "push" factors in the nurses' country of origin can be related to low pay, poor career prospects and in many cases instability and violence. The "pull" factors exerted by many destination countries include better pay, career and educational opportunities [23]. It is difficult for developing countries to compete in the global market for nurses. The salary disparity between low- and high-income countries means low-income source countries cannot hope to match the pay that is on offer in the high-income destination countries. There is an increasing debate about the ethical dimension of international recruitment activity [25]. There is a need to evaluate new models and policies. This can include bilateral agreements between countries, and the use of "managed migration" initiatives, such as those being tested in the Caribbean [26] and highlighted in the Commonwealth Secretariat International Code of Practice [27]. Research indicates that nurses are attracted to and retained at their work because of opportunities to develop professionally, to gain autonomy, to participate in decision-making and to be fairly rewarded $[28,29]$. Workplace factors can be critical influences on the turnover of nursing staff [30-36]. There is some evidence that a participative management style, flexible employment opportunities and access to continuing professional development can facilitate the retention of nursing staff as well as improve patient care [37-40].

Many of these issues are addressed in the "magnet hospital" model which has developed over the last 20 years. The concept of the magnet hospital was developed initially in the 1980 s in the United States [40]. The initial focus of that research was to identify the human resource practices and associated organizational characteristics that enabled these hospitals to attract and retain staff, even in difficult labour market conditions. The research highlighted that these improvements in staffing indicators are also related to improvements in patient care. The idea of the magnet institution has been sustained and developed over the successive decades through a series of research studies [34] and by the development of a magnet nursing services accreditation programme $[41,42]$. This, and similar approaches, are now being investigated in several countries. In 2009, the nursing service of the American University of Beirut medical centre was recognized as a "magnet hospital", thus providing a model for other medical centres to follow suit. 
Role of the World Health Organization

The development of human resources for health has been a vital area for WHO EMRO's collaborative work with member states ever since its inception half a century ago [43]. While the commitment of WHO EMRO to human resources for health development has remained steady, the focus of its collaborative development work in this field has shifted over the years, in parallel with the different phases of development of health systems and human resources in member states.

In the 1960s, WHO's technical collaboration was directed towards expanding and bolstering national capacities for the production of the main categories of health personnel. This goal was pursued through the provision of assistance to countries in the form of long-term fellowships for training professionals, the fielding of expatriate trainers and the procurement of equipment, appropriate technology and essential supplies for the implementation of national training programmes. At the same time WHO EMRO started providing technical assistance to ministries of health to establish structures such as training departments and units responsible for the management of human resources for health and training activities in the countries of the region.

In the 1970s, EMRO began to prioritize its assistance to selected areas, and public health, nursing and allied health personnel training programmes were targeted. This was in line with health care delivery strategies advocated by $\mathrm{WHO}$ at the time, and adopted by the EMRO countries, which emphasized the delivery of maternal and child health services. Later, the integrated health care delivery model evolved out of these strategies.

By the late 1970s strategies began to focus on improving the quality and performance of human resources.
WHO EMRO was a pioneer in the international movement towards the reform of training curricula to become more community-oriented and thus more relevant to people's needs, and it supported several institutions in the region in this regard. The University of Gezira in Sudan and Suez Canal University in Egypt were among the founding members of the international movement towards community-based medical education. Special efforts were also made in 1981 to adopt a community-oriented medical curriculum in the Faculty of Health Sciences of the Gulf University in Bahrain [N. Kronfol. Feasibility study on the establishment of the Gulf University Medical School in Bahrain. WHO assignment report January 1981]. This author has observed that medical colleges of Tikrit and Basra in Iraq and of Hadramaut in the Yemen have developed strong community health departments with opportunities for field practice for medical students. Institutions in the region also were supported to adopt the most effective and up-to-date training methodologies and access quality training/learning resources. Educational development centres were established in most countries of the region.

The lack of human resources remains aggravated by imbalances in skill mixes, by inequitable distribution of resources inside the countries, and by internal as well as external migration of professionals. Health professionals in the Arab region were, and still are, trained in non-mother-tongue languages (for example English, French or Italian, depending on the colonial legacy), with the notable exception the Syrian Arab Republic, which spearheaded the teaching of medicine and all other health professions in Arabic language, while Egypt, Sudan and Iraq adopted a partial approach to the use of the national language..

Special programmes were also established by WHO EMRO to support the use of national languages in the education of health professionals. Strong efforts were made to initiate, develop and consolidate the Arabization programme in collaboration with several educational associations, principally the regional office of the United Nationals Educational, Scientific and Cultural Organization (UNESCO) and the Islamic States Educational, Scientific and Cultural Organization (ISESCO).

In 2000, EMRO began working towards the launch of a new initiative for the reform of education of medical and health professionals in the region. Development of partnerships was adopted as an essential strategy of the initiative. Guidelines on reform interventions were prepared and adopted in May 2002 [44,45]. The changing roles of health professionals in the face of evolving health needs figured prominently in these reforms. Some of the recommendations proposed by EMRO and other professional bodies highlighting the social accountability and civic orientation of medical colleges have been recently espoused by the Lancet Commission on Medical Education [46].

Nevertheless, despite the progress achieved in recent years in reforming and improving performance of the health care system and the practice and education of health professionals, key challenges are still faced in any effort to improve relevance, equity, costeffectiveness and quality. In the health services of a range of countries across the region, there is evidence of considerable investment in facilities and services but often with limited attention to support for management infrastructure and capacity [47]. In other words, the development of human resources has not always kept pace with the physical development of the services, leading to a steady increase in inefficiency and ineffectiveness in the provision of health care. Prominent obstacles for workforce development have been identified and include [48]: 
- The absence of a comprehensive national health development strategy for the health sector.

- The education programmes of academic institutions are not linked to the needs of the country.

- Admission policies to institutions of higher education and universities are often unrealistic.

- Too little attention is given to continuing education of health professionals.

- Primary health care and non-clinical activities are overlooked.

- There is little or no coordination between ministries of health, universities, training institutions and the public.

\section{Training in management}

Education in the disciplines of epidemiology, health administration and biostatistics can offer a long-term solution to the problem of lack of expertise in planning and management of health services. Unfortunately, despite the plethora of medical schools that have mushroomed, very few schools of public health have been developed in the past 30 years in the region. The High Institute of Public Health in Alexandria, Egypt, and the School of Public Health at the American University of Beirut, Lebanon, have contributed to preparing public health professionals from all countries of the region since the 1950s. Since the 1980s, WHO EMRO had drawn attention to the urgent need for a cadre of trained leaders and managers to lead, develop, direct and manage the health care facilities and programmes in all countries of the region. There have been several initiatives in this field over the last 2 decades, namely the Leadership Development Programme, the Postgraduate Diplomas in Public Health, the Sudan Medical Specialization Board, the collaborative training programme on Leadership and Management, the Health Academy [48], the Management Effectiveness Programme [49] and the Health Leadership Service. The Leadership Development Programme started in 1989 in EMRO with participants from a large number of countries of the region. The goal of the programme was the development of young leaders who will lead and manage their national health systems.

In 1983, and at the invitation of the Executive Committee of the Council of Arab Ministers for Health, WHO EMRO assisted in the planning and implementation of a Masters in Epidemiology programme at Ain Shams University in Cairo [N. Kronfol, unpublished report]. The aim of the programme was to train epidemiologists from the Arab countries to return to their countries and assist in the implementation of an epidemiological mapping exercise for the region.

EMRO in 1988 invited 2 consultants to propose a curriculum for a Diploma in Public Health [N. Kronfol, M. Khojali, unpublished report]. The proposal was approved and programmes were established in the Syrian Arab Republic in 1989 and in Jordan in 1991. The Syrian Arab Republic continued with this programme and today almost all health care facilities in the country house graduates of their Institute of Public Health who proved to be a very effective element in the development and management of all the health care system facilities in the country. The School of Health Management was established in Damascus in 1997 to train public health professionals and strengthen the management capacity of the health workforce. In 2000, a joint teaching initiative was entered into with the Liverpool School of Tropical Medicine in the United Kingdom, WHO and the United Nations Population Fund, to develop the management skills of students. In addition to the former programme, Jordan, in collaboration with WHO, developed a Community Medicine Programme to prepare physician district managers. More recently Bahrain has established the Health Management Programme in collaboration with the Royal College of Physicians (Ireland). Morocco, Tunisia and Algeria have established the Reseau de l'Economie des Systemes de Santé dans les pays du Maghreb Arabe (RESSMA), a francophone regional network on Health Economics and Health Systems Research that has been conducting a yearly block course in Health Economics over the past several years in French with input from WHO and other agencies. In addition to these formal programmes, WHO EMRO has developed training modules in the areas of management with a special focus on health economics. These courses have included the basic concepts of planning, the conduct of national health accounts and the burden of disease methodology. EMRO has also cooperated with the World Bank in offering courses within the World Bank Institute's Flagship Program. Modules of this programme have been offered in Lebanon, Islamic Republic of Iran, Yemen and Jordan.

Other programmes include a scheme that has been instituted in the UAE in collaboration with EMRO and the International Council of Nurses to help prepare nurses and allied health professionals for management and leadership positions. The Health Academy is a WHO initiative in collaboration with Cisco Systems Inc. that will provide health professionals with online training in health information and health management [48]. The Management Effectiveness Programme has been introduced by a number of countries of the region including Syrian Arab Republic and Egypt, who have adapted its elements according to their own specific strategy for improving the management of health care services and health outcomes [49]. Finally, the 
mission of the Health Leadership Service is to provide an intensive 2-year supervised work experience to selected health professionals under 38 years of age that equips and motivates them to become health leaders committed to achieving the goals of "health for all”, whether working at community, national or international levels [47].

In order to promote primary health care, graduate programmes of family medicine have been introduced into the universities in most countries. The first countries to take thelead were Lebanon, with its Family Medicine programme at the American University of Beirut (AUB) in 1978, and Bahrain, with a programme for the Ministry of Health also in cooperation with AUB. The commitment of nations to primary care was also reflected in educational policies and innovative training schemes.

Reforms of the health sector are being undertaken by many Arab countries. Health financing, cost-effectiveness and access to quality services are the components of reform receiving the most attention. These and other factors that can contribute to improving the performance of the health services will require enhanced human resources which need to be defined and developed accordingly.

\section{Summary}

Preparing a health workforce to meet today's challenges is more likely to be achieved if the universities of the region in general, and medical schools and other health professionals' training schools in particular, are strong and flexible. Curricula will need to be modernized to meet these challenges and respond to the needs of the communities and in partnership with them.

Universities and medical schools will need to improve the fitness-forpurpose of medical graduates. There is a need for continual integration and collaboration between the education system and the health system (an academic and service continuum), as well as an inter-professional approach to developing human resources. Medical education globally is changing in line with changes in society, to which the medical profession and other health and allied professions are responding, adapting or planning ahead.

The shift in balance between hospital inpatient services and those provided by primary and community services has tremendous influence on the practice of medicine today. Practitioners have to be aware of traditional/ complementary medical practices and treatments; they have to work within a team in collaboration with colleagues in primary care, social services and other organizations within society.

Health professional education is changing too [46]. These changes are in line with changes in society to which the medical profession and other health and allied professions are responding, adapting and planning ahead. There are many external and internal factors today which influence the theory and practice of medicine. These include changes in the level of morbidity and disease patterns, expectations for the health services, demand for a delivery of high quality care, changing health care needs, medical advances and technology and inter-professionalism in the future workforce

The last 3 decades have witnessed important developments in the number and diversities of health professionals in the Arab states. The time has come to expand efforts towards further development in the quality and relevance of education, the professional development of health professionals, their service and commitment to improve the health systems and the welfare of communities and the production of research and studies in cooperation with policy-makers to enhance decisions and policies based on evidence.

\section{References}

1. Kronfol NM. Historical development of health systems in the Arab countries: a review. Eastern Mediterranean Health Journal, 2012, 18(11):1151-1156

2. Kronfol NM. Delivery of health services in the Arab region: a review. Eastern Mediterranean Health Journal, 2012 [in press].

3. Kronfol NM. Access and barriers to health care delivery in the Arab countries: a review. Eastern Mediterranean Health Journal, 2012 [in press].

4. Kronfol NM. Health services to groups with special needs in the Arab world: a review. Eastern Mediterranean Health Journal, 2012 [in press].

5. Okasha MS, Ziady HH. Joining the nursing profession in Qatar: motives and perceptions. Eastern Mediterranean Health Journal, 2001, 7(6):1025-1023

6. Munro BH. Young graduate nurses: who are they and what they want? Journal of Nursing Administration, 1988, 13:21-26.
7. Mansour AA. Nursing in Saudi Arabia as perceived by university students and their parents. Journal of Nursing Education, 1992, 32:45-46.

8. Abugharbieh M, Suliman W. Changing the image of nursing in Jordan through effective role negotiation. International Nursing Review, 1992, 39:149-152.

9. Jucker J. Women in nineteenth century in Egypt. Cambridge, Cambridge University Press, 1985.

10. Meleis AI. A model for establishment of educational program in developing countries: The nursing paradoxes in Kuwait. Journal of Advanced Nursing, 1980, 24:289-293.

11. Nursing education in the Eastern Mediterranean Region. Alexandria, World Health Organization Regional Office for the Eastern Mediterranean, 1998 (EMRO Technical Publications Series 26).

12. Annual report of the Regional Director. Alexandria, World Health Organization Regional Office for the Eastern Mediterranean, 1996. 
13. Annual report of the Regional Director. Alexandria, World Health Organization Regional Office for the Eastern Mediterranean, 1997.

14. Annual report of the Regional Director. Alexandria, World Health Organization Regional Office for the Eastern Mediterranean, 1998.

15. Annual report of the Regional Director. Alexandria, World Health Organization Regional Office for the Eastern Mediterranean, 1999.

16. A strategy for nursing and midwifery development in the Eastern Mediterranean Region. Alexandria, World Health Organization Regional Office for the Eastern Mediterranean, 1997 (WHO EMRO Technical Publications Series 25).

17. International migration of health personnel: a challenge for health system in developing countries. Resolution at the fiftyseventh World Health Assembly, 22 May 2004 (WHA57.19).

18. Fargues P. Arab migration to Europe: trends and policies. In: Arab migration in a globalized world. Cairo, League of Arab States, International Organization for Migration, 2004.

19. International migration report 2009: a global assessment. New York, NY, United Nations, Department of Economic and Social Affairs, Population Division, 2011 (ST/ESA/SER.A/316).

20. Kronfol N. The migratory patterns of the medical graduates of the American University of Beirut 1935-1974 [PhD thesis]. Boston, Massachusetts, Harvard School of Public Health, University of Harvard, 1979.

21. Kronfol NM, Sibai AM, Rafeh N. The impact of civil disturbances on the migration of physicians: the case of Lebanon. Medical Care, 1992, 30:208-215.

22. Kronfol NM, Rafeh N. The impact of civil disturbances on the migration of physicians: the case of Lebanon. Health Matrix, 1987, 5:29-35.

23. Ronaghy HA, Williams KN, Baker T. Immigration of Iranian physicians to the US. Journal of Medical Education, 1972, 47(6):443-445.

24. Ronaghy H, Cahill K, Baker T. Physician migration to the United States: one country's transfusion is another country's hemorrhage. Journal of the American Medical Association, 1974, 227(5):538-542.

25. Buchan J, Calman L. The global shortage of registered nurses: an overview of issues and actions. Geneva, International Council of Nurses, Global Nursing Review Initiative, 2005.

26. Salmon ME et al. Managed migration: the Caribbean approach to addressing nursing services capacity. Health Services Research, 2007, 42:1354-1372.

27. Commonwealth Code of Practice for the International Recruitment of Health Workers. Adopted at the Pre-WHA Meeting of Commonwealth Health Ministers 2003, Geneva on Sunday 18 May 2003 (http://www.thecommonwealth.org/ shared_asp_files/uploadedfiles/\%7B7BDD970B-53AE-441D81DB-1B64C37E992A\%7D_CommonwealthCodeofPractice. pdf, accessed 1 October 2012).

28. Irvine D, Evans M. Job satisfaction and turnover amongst nurses: Integrating research findings across studies Nursing Research, 1995, 44:246-253.

29. Shields M, Ward M. Improving nurse retention in the National Health Service in England: the impact of job satisfaction and intentions to quit. Journal of Health Economics, 2001, 20:677-701.

30. Baumann A et al. Commitment and care: the benefits of a healthy workplace for nurses, their patients and the system: final report. Ottawa, Canadian Health Service Research Foundation, 2001.

31. Duffield C, O'Brian-Pallas L. The nursing workforce in Canada and Australia: two sides of the same coin. Australian Health Review, 2002, 25:136-144.
32. Aiken L et al. Hospital nurse staffing and patient mortality, nurse burnout, and job dissatisfaction. Journal of the American Medical Association, 2002, 288:1987-1993.

33. Aiken $L$ et al. Nurses' reports on hospital care in five countries. Health Affairs, 2001, 20(3):43-53.

34. Atencio B, Cohen J, Gorenberg B. Nurse retention: is it worth it? Nursing Economics, 2003, 21:262-268.

35. Tuttas C. Robbing Peter to pay Paul: breaking the RN "recruitment cycle". Journal of Nursing Care Quality, 2002, 16:39-45.

36. Stone $S$ et al. Evidence of nurse working conditions: a global perspective. Policy, Politics and Nursing Practice, 2003, 4:120130.

37. Aiken L, Smith H, Lake E. Lower Medicare mortality amongst a set of hospitals known for good nursing care. Medical Care, 1994, 32:771-787

38. Clarke $\mathrm{H}$ et al. Nursing shortages: workplace environments and essential to the solution. Healthcare Quarterly, 2001, 4(4):50-58

39. Heinz D. Hospital nurse staffing and patient outcomes: A review of current literature. Dimensions of Critical Care Nursing, 2004, 23:44-50.

40. McClure M et al. Magnet hospitals: attraction retention of professional nurses. Kansas City, Missouri, American Academy of Nursing, 1983.

41. Kramer M, Schmalenberg C. Essentials of a magnetic work environment. Nursing, 2004, 34:50-54.

42. Magnet Nursing Service Recognition Program. Health care organizations instructions and application profess manual 2001-2002. Washington DC, American Nurses Credentialing Center, 2003.

43. The work of the World Health Organization in the Eastern Mediterranean Region. Annual report of the Regional Director. Cairo, World Health Organization Regional Office for the Eastern Mediterranean Region, 2004.

44. Report of the meeting of the expert group on reform of health professions education in the Eastern Mediterranean Region, Cairo, Egypt, 31 March-2 April 2002. Cairo, World Health Organization Regional Office for the Eastern Mediterranean, 2002 (WHO-EM/HRH/591/E/R)

45. World Federation for Medical Education international guidelines: quality improvement in basic medical education. Copenhagen, University of Copenhagen, 2001.

46. Frenk J et al. Health professionals for a new century: transforming education to strengthen health systems in an interdependent world. Lancet, 2010, 376:1923-1958.

47. Role of academia and professional associations in support of health for all. A paper submitted to the forty-fourth session of the WHO/ EMR Regional Committee, October 1997. Cairo, World Health Organization Regional Office for the Eastern Mediterranean. 1997.

48. Health Academy. World Health Organization [website] (http:// www.who.int/healthacademy/en/, accessed 1 October 2012).

49. WHO Management Effectiveness Program in EMR States (MEP). Health Care International [website] (http://hci.com.eg/resources/publications/who-management-effectiveness-program-in-emr-states-mep-1, accessed 1 October 2012).

50. Regional Committee for Eastern Mediterranean. Health manpower development in countries of the Eastern Mediterranean Region. Genera, World Health Organization, 1986 (EM) RC33/11).

51. Global Health Observatory data repository. World Health Organization [online database] (http://apps.who.int/ghodata/, accessed 1 October 2012) 